\title{
Salmonella osteomyelitis of the thoracic spine: an unusual presentation
}

\author{
S K Gupta, A Pandit, D G White, P D Evans
}

Postgrad Med J 2004;80:1 10-111. doi: 10.1136/pmj.2002.002592

\begin{abstract}
A case of thoracic vertebral osteomyelitis due to Salmonella enteritidis phage type 2 in an immunocompetent patient is reported. The patient initially presented with abdominal, urinary and chest symptoms, which were followed by a large pleural effusion. The infection was successfully treated with ciprofloxacin. This is the only case of salmonella thoracic vertebral osteomyelitis in an immunocompetent patient reported in the English literature.
\end{abstract}

A 17 year old white girl presented with acute left loin pain and dysuria. She had a history of contact with her mother's parrot, which had died two months previously. On examination, she had slight tenderness in her left iliac fossa. Her white cell count was raised to $13.6 \times 10^{9} / 1$. A provisional diagnosis of urinary tract infection was made, and she was prescribed oral ciprofloxacin.

Three days later she developed right pleuritic chest pain and a productive cough with green sputum. She had pyrexia of $38^{\circ} \mathrm{C}$, and chest auscultation revealed crepitation at both lung bases. A chest radiograph was normal. On blood analysis, alkaline phosphatase was $386 \mathrm{U} / \mathrm{l}$ (normal range 50-136 U/l), C-reactive protein was $256 \mathrm{mg} / \mathrm{l}$ (normal range less than $10 \mathrm{mg} / \mathrm{l})$, and erythrocyte sedimentation rate was $76 \mathrm{~mm}$ in the first hour. An ultrasound of her abdomen revealed a minor splenic enlargement and bilateral small pleural effusions. A working diagnosis of atypical pneumonia was made.

Ciprofloxacin was discontinued, and she was prescribed intravenous cefuroxime and oral clarithromycin. Her signs and symptoms improved on this treatment, and two weeks after admission she was discharged home.

Four weeks later she was readmitted with pain in her lower thoracic and lumbosacral area and lateral chest walls, a history of night sweats, and a weight loss of over $6 \mathrm{~kg}$ in one month. On chest examination, there was no air entry at the right lung base. She was extremely tender over the sacrum and lower back. Her white cell count was raised to $19.1 \times 10^{9} /$, her erythrocyte sedimentation rate was $78 \mathrm{~mm}$ in the first hour, and her C-reactive protein was $114 \mathrm{mg} / \mathrm{l}$. Chest radiography revealed a large right pleural effusion (fig 1). A bone scan showed a hotspot at the ninth and tenth thoracic vertebrae (T9-T10). The pleural effusion was aspirated and found to be negative for culture and acid fast bacillus. She was treated with intravenous cefuroxime and clarithromycin for one week, but her temperature did not settle, and hence she was given intravascular injections of imipenem after which her condition settled. A chest drain was inserted, and she was given 250000 units of streptokinase intrapleurally twice a day for three days.

Computed tomography of the thoracic spine with contrast showed a loss of height of the Tl0 vertebra with evidence of widespread oedema of the bone marrow

\section{Summary points}

- This case demonstrates that thoracic vertebral Salmonella osteomyelitis can present as a pleural effusion giving rise to chest symptoms.

- Osteomyelitis of the thoracic vertebrae should be among the factors considered to contribute to pleurisy and/or pleural effusion.

spreading up into the anterior portion of T9 and affecting the superior portion of Tll. This finding is consistent with vertebral osteomyelitis. There was a paraspinal mass of soft tissue around these vertebrae (fig 2). A needle aspiration of the abscess grew Salmonella enteritidis phage type 2. The vertebral osteomyelitis was treated successfully with ciprofloxacin $500 \mathrm{mg}$ twice a day for eight weeks, after which she was asymptomatic and her erythrocyte sedimentation rate and $\mathrm{C}$-reactive protein were within the physiological range.

\section{DISCUSSION}

Salmonella causes a broad spectrum of human illnesses from gastroenteritis, typhoid fever, and bacteraemia to the asymptomatic carrier state. ${ }^{12}$ Salmonella has been recognised as a causative organism of osteomyelitis for more than a century; however, it is a rare cause of osteomyelitis, accounting for approximately $0.5 \%$ of all cases. ${ }^{3}$ Only 67 cases of salmonella bone and soft tissue infections were reported to the Communicable Disease Surveillance Centre in England and Wales between 1992 and 2000.

Salmonella osteomyelitis is usually seen when the patient is immunologically compromised. In addition to sickle cell

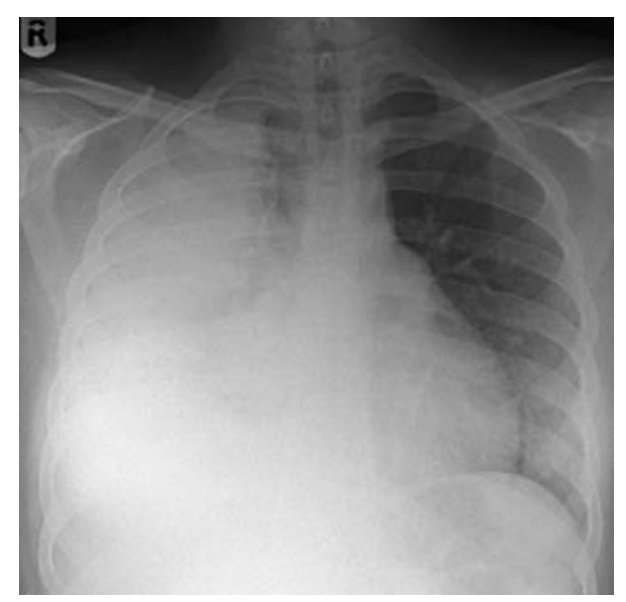

Figure 1 Chest radiograph showing right sided pleural effusion. 


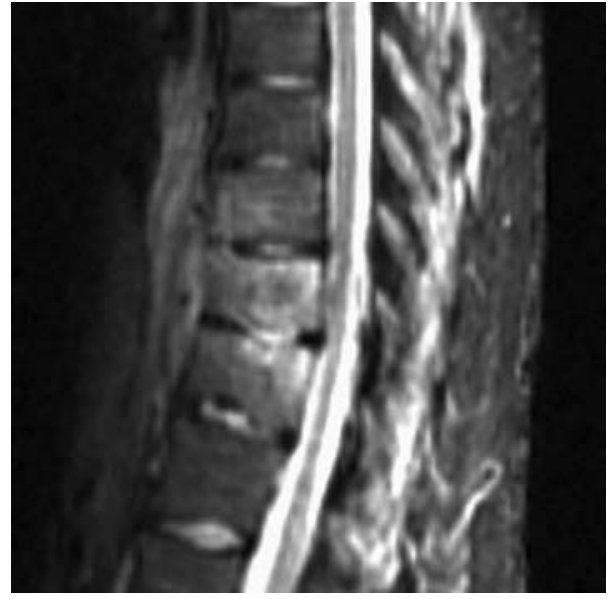

Figure 2 Magnetic resonance imaging scan showing osteomyelitis of T9, T10, and T11 with paraspinal mass of soft tissue.

disease, ${ }^{4}$ conditions that may compromise the immune system include chronic alcoholism, ${ }^{5}$ chronic lymphocytic leukaemia, systemic lupus erythematosus, neoplastic disease, long term steroid intake, ${ }^{6}$ and possibly AIDS. Our patient did not have any of these predisposing factors.

Santos et al reviewed 44 cases of salmonella vertebral osteomyelitis published in the English literature between 1966 and June 1997. ${ }^{7}$ They found that fever and back pain were the main symptoms on presentation. However, Shimada et al did report a case of vertebral osteomyelitis due to Salmonella newport associated with a bilateral pleural effusion in a leprous patient in $1996 .{ }^{8}$ The infection was considered to have been precipitated by haemolytic anaemia resulting from the use of dapsone. Carr and Crow $^{9}$ and Sullivan et al ${ }^{10}$ each reported a case of vertebral osteomyelitis presenting with pleural effusion, but the pathogen was staphylococcus in each case.
This case demonstrates that thoracic vertebral salmonella osteomyelitis can present as a pleural effusion giving rise to chest symptoms, which may be due to a reactive pleuritis as the pleura is in close contact with the thoracic vertebrae.

Osteomyelitis of the thoracic vertebrae should be among the factors considered to contribute to pleurisy and/or pleural effusion.

\section{Authors' affiliations}

S K Gupta, A Pandit, D G White, P D Evans, Department of Orthopaedics, Medicine and Microbiology, Royal Glamorgan Hospital, Llantrisant, Pontyprid, UK

Correspondence to: Mr S K Gupta, 13 Clos Cwm Du, Pontprennau, Cardiff CF23 8LE, UK; sanjaygupta123@hotmail.com

Submitted 28 October 2002

Accepted 7 February 2003

\section{REFERENCES}

1 Rubin RH, Weinstein L. Salmonellosis: microbiologic, pathologic and clinical features. New York: Startton Intercontinental Medical Book Corp, 1977.

2 Miller SI, Hohman EL, Pegues DA. Salmonella (including Salmonella typhi). In: Mandell GL, Bennett JE, Dolin R, eds. Mandell, Douglas and Bennett's priniciples and practice of infectious disease. 4th Ed. New York: Churchill Livingstone, 1995:2013-33.

3 Ortiz-Neu C, Marr JS, Cherubin CE, et al. Bone and joint infections due to salmonella. J Infect Dis 1978;138:820-8.

4 Givner LB, Luddy RE, Schwartz AD. Etiology of osteomyelitis in patient with major sickle haemoglobinopathies. J Pediatr 1981;99:411-13.

5 Brayton RG, Stoles PE, Schwartz MS, et al. Effect of alcohol and various diseases on leucocyte mobilization, phagocytosis and intracellular bacterial killing. N Engl J Med 1970;282:123-8.

6 Engh CA, Hughes JL, Abrams RC, et al. Osteomyelitis in patients with sickle cell disease, diagnosis and management. J Bone Joint Surg Am 1971;53:1-15.

7 Santos EM, Sapico LF. Vertebral osteomyelitis due to salmonellae: report of two cases and review. Clin Infect Dis 1998;27:287-95.

8 Shimada T, Nishimura Y, Kimura G, et al. Vertebral osteomyelitis presenting with bilateral pleural effusion in a leprous patient. Diagn Microbiol Infect Dis 1996;24:101-3.

9 Carr AJ, Crow PG. Vertebral osteomyelitis presenting with abdominal pain and pleural effusion. J R Coll Surg Edinb 1987;32:373-4.

10 Sullivan PJ, Currie D, Collins JV, et al. Vertebral osteomyelitis presenting with pleuritic chest pain and bilateral pleural effusion. Thorax 1992;47:395-6. 